\title{
Association of Brazilian Adolescents with Healthy Eating: Knowledge, Perceptions and Food Choices
}

\author{
Ana Carolina Barco Leme, Sonia Tucunduva Philippi, Érika Christiane Toassa da Silva
}

Department of Nutrition, School of Public Health, University of São Paulo, São Paulo, Brazil.

Email: leme.acarolina@usp.br

Received July 27 ${ }^{\text {th }}$, 2011; revised August 26 $6^{\text {th }}, 2011$; accepted September $5^{\text {th }}, 2011$.

\begin{abstract}
The aim of this study is to identify the adolescents' knowledge and perceptions of healthy and unhealthy eating. It is a qualitative cross section study with 83 adolescents of both genders between 10 and 16 years old enrolled in a public school in the city of São Paulo, Brazil. The participants answered two discursive questions that assessed their knowledge and perception of their actual diet. These questions were later analyzed by a qualitative technique, "Discourse of Collective Subject" based on the Theory of Social Representations. Overall, the youth presented an adequate knowledge about healthy eating. About half (52.6\%) reported a balanced and varied diet; and 56.3\% considered their actual diet as being healthy. Adolescents' knowledge about healthy eating isn't the only determinant for their food choices; and so traditional nutritional interventions focusing on concepts about healthy eating should be modified, aiming at behavioral changes.
\end{abstract}

Keywords: Adolescents, Healthy Eating, Qualitative Study, Knowledge and Perceptions

\section{Introduction}

Obesity and overweight can lead to the development of several diseases, such as type 2 diabetes, hypertension, dyslipidemia and metabolic syndrome [1]. Overweight children and adolescents frequently present lower selfesteem, which can affect their school performance and relationships, leading to psychological consequences in the long term [2]. This group is of great concern, due to their higher chances of being in this condition when adults. TRAEBERT et al. [3] mention that the risk for an obese child to remain obese in his/her adulthood is $25 \%$, increasing to $80 \%$ when overweight settles during adolescence.

According to the Brazilian House Budget Survey conducted in 2008-2009, 20.5\% of the Brazilian adolescents were considered overweight and $4.9 \%$ were obese, being that $21.5 \%$ and $19.4 \%$ of the boys and girls, respectively were overweight and, $5.8 \%$ of the boys and $4 \%$ of the girls were obese. The highest prevalence of overweight and obesity (20\% - 27\%) among adolescents of both genders was found in the following regions: Midwest, South and Southwest. The study was conducted in the latter one [4].

While the nutritional intake during childhood and adolescence is important for physical growth, the develop- ment of lifelong eating behaviors may have long term health implications [5]. The quality of adolescents' diets has become of growing concern for researchers and health professionals. Studies all over the world have consistently shown that many adolescents have poor dietary habits, which do not meet the recommended dietary guidelines. They are increasingly consuming foods rich in fat, sugar and salt, and have a low intake of fruits, vegetables, whole grains and dairy groups of the food pyramid or other dietary guidelines [6-8].

The food choices of youth are influenced by a number of determinants, including "collective" factors such as nutritional knowledge, peers, parenting practices, family characteristics, the fast-food industry, mass media, food fads, and social/cultural norms and values. "Individual" factors such as psychological needs, body image, selfconcept, food preferences, psychosocial development, personal values, beliefs, and food meanings are also influential [9-12].

Many of these factors have received a great deal of research attention, but there is little knowledge of the symbolic meanings associated with healthy eating, especially from the perspective of adolescents. The meanings associated with food and nutrition are of great interest to their influence and determination on the consumption of a particular food [13,14]. 
Studies have shown that nowadays cultural attitudes toward food are usually based on health concern $[13,14]$, and food is most times dichotomized into "healthy" and "unhealthy" categories. This dichotomy is paired with descriptors such as "good" and "bad" for healthy and unhealthy foods, respectively [15-17].

The term research for many food and nutrition professionals is related to a quantitative approach that includes data, numbers, measurement, controls, controlled environments, reliability, randomized clinical trials, interventions and outcomes. On the other hand, when a phenomenon is not easily measured, processes must be evaluated, knowledge about a culture is limited, or reasons for outcomes must be discerned, a different approach is needed [18].

The best approach to the aforementioned situations is the qualitative research, which is particularly relevant to the applied science of dietetics, for example, when the main purpose of the study is the behavioral variability such as thoughts, feelings and attitudes. Under the view of the empiric social sciences there are three main approaches to understand the behavior status: 1 ) to look for the behavior that occurs naturally in real situations; 2) to create artificial situations and observe the behaviors of the subjects involved in these situations; and 3) to identify people's responses to the situations and/or behaviors [19].

Qualitative studies produce findings not derived from standard statistical procedures or other means of quantification. They are defined as a naturalistic approach that seeks to understand phenomena in uncontrolled, context-specific settings, in which data are not numbers, but text, audio or visual contexts [18-20]. The purpose of qualitative research is to discern the meanings people give to their experiences. It is of utmost importance to understand phenomena from the perspective of the research participants [18].

The data collected from a qualitative research can be obtained in several ways such as focus groups, interviews, observations, internal and external documents, photograph inspection and internet methods. Interviews can be conducted with individuals, and each member of a sample is interviewed to obtain detailed data such as their experiences, opinions and knowledge. In other words, these are the thoughts of a collectivity [18,21]. Taking into account the fact that collective opinion as an empirical fact is conveyed only indirectly by the researcher's meta-discourse or by means of a given mathematical formula (losing its immanent form) one proposes as a truly expressive alternative the Discourse of Collective Subject (DCS) [22].

The proposal of the DCS is grounded mainly in the propositions of the Theory of Social Representations [23].
It lists and articulates various operations on a raw data constituted of statements obtained through empirical polling using open-ended questions, resulting in collective statements made up of different extracts of individual statements. Each collective statement stands for a determined opinion or position and is written in the first person singular aiming at producing in the receptor the effect of a collective opinion expressed as an empirical fact through the "mouth" of a single subject discourse [22]. To sum up, the Discourse of the Collective Subject is like one person expressing the opinion of a collectivity.

The application of the DCS technique to empirical research in the field of public health and also in other fields has shown its efficacy for the processing and expression of collective opinions [22].

Thus, the aim of this study is to identify the adolescents' knowledge and perceptions about healthy and unhealthy eating, as well as the enablers and barriers for its achievement.

\section{Material and Methods}

Qualitative methods were used to collect data through interviews. Because perceptions of health and lifestyle cannot be readily quantified, qualitative methods enhance understanding of these phenomena through rich descriptions of topics of interest [24]. A semi-structured interview is carried out with open-ended questions in which the participants are free to express opinions, ideas, meanings and thoughts as to how they experience their social and cultural world and so the data are detailed, comprehensive, more representative of the phenomenon, and less biased [18].

\subsection{Study Design and Sample}

This was a cross-sectional study conducted in 2009 involving adolescents of both genders, ranging from 10 to 16 years of age, who were enrolled in a public school in the city of São Paulo. The students voluntarily enrolled in the study. Prior to the acceptance, children's parents or guardians were fully informed about the objectives and methods of the study and signed an informed consent. Nearly all the adolescents assigned for the study participated in it. Those who didn't participate were not present on the day of the interview and/or hadn't brought the consent signed by their parents or guardians.

\subsection{Data Collection}

Students enrolled in 5th and 8th grades of fundamental school were invited to participate in the study. One class of each grade was selected for the study (Figure 1), once the construction of the Discourse of Collective Subjective (DCS) does not require a big sample. A selection of 
the most relevant characteristics of the population was thus obtained for the study [22].

Since the students in each class differ in ages and genders, they could compose a diverse and representative sample for this study and, consequently for the discourse construction.

\subsection{Pre-Test}

The questionnaire for the interview was previously tested in a similar sample of adolescents (ages and genders). After the pre test, some adjustments were made to the format of the questions adapting them to the aim of each question.

\subsection{Questionnaire for the Interview}

To analyze the adolescents' meanings and perceptions of their diet, identifying their own concept of healthy eating and the enablers and barriers to adopt or not to adopt them, a questionnaire with 2 discursive questions was applied (Box 1). The students were free to give their own opinion related to the proposed topic.

The participants were informed about the questionnaire content and were free to address the issues in their own way. They were also informed that were no right or wrong answers. They were accommodated in a comfortable way to answer the questionnaire during P.E. class.

\subsection{Data Analysis}

For the data analysis the Discourse of Collective Subject methodology was used, consisting of a methodological

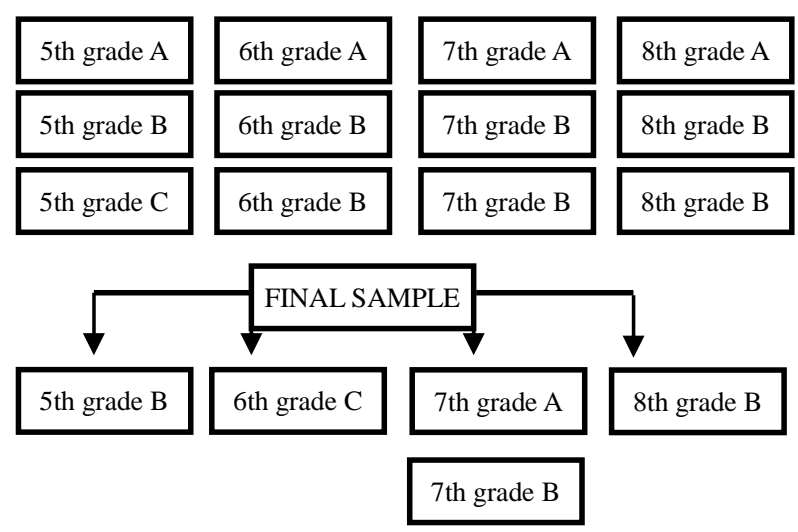

Figure 1. Selection of the adolescents of the study.

1) In your opinion what does healthy eating mean?

Aim: to identify the adolescents' concept about healthy eating.

2) Do you consider your diet healthy? Why or Why not? Aim: to identify the adolescents' own perceptions about their diet, as well as the enablers and barriers to adopt them.

Box 1. Discursive questions and its aims used in the study. resource to rescue collectivity opinions in a quail-quantitative way. It allows a particular social group to express a given thought or social representation about a phenomenon [22].

For the analysis of this technique the discursive data was assessed by the following methodological figures: key expressions and central ideas, which were selected from each individual answer to a given question.

The key-expressions are the most significant excerpts of the answers, and they correspond to the central ideas. The central ideas are the synthesis of the discursive content expressed in these key-expressions. The synthesis of the discourse is built from a varied number of individuals in the first person of the singular. These results are going to become the Discourse of Collective Subject (DCS) [22]. In Box 2 the steps to develop the DCS are shown:

\subsection{Ethical Aspects}

Study procedures were approved by the School of Public Health, University of São Paulo Ethic Committee and by the principal of the participating school. Adolescents were allowed to participate in the study provided that they brought their parents or guardians' signature on the consent term, which also explained briefly the aims of the study.

\section{Results}

In total, 83 adolescents participated in this study, being that 33 (39.8\%) were boys and 50 (60.2\%) were girls between ages 10 and 16. As to the proportion of participants in each grade according to gender, the majority of girls were enrolled in 7th grade (34.62\%) and the majority of boys in 5 th grade $(29.03 \%)$.

The adolescents' concepts and perceptions about healthy and unhealthy eating, as well as the enablers and barriers to reach them were shown as follows below.

The first question "In your opinion what does healthy eating mean?” produced 97 key expressions that resulted in 5 central ideas: "It's to have a balanced and varied diet", "to eat fruit and vegetables", "to control fat, sweet, pasta and salty foods", "to eat at regular times" and "to

\footnotetext{
$\mathbf{1}^{\text {st }}$ The questions were analyzed separately. The whole content of the answers that referred to each question was copied.

$2^{\text {nd }}$ The key-expressions were identified.

$3^{\text {rd }}$ The central ideas were identified from the key-expressions.

$4^{\text {th }}$ The central ideas that have the same, similar or complementary meaning were identified and clustered. Each cluster was categorized with letters: $\mathrm{A}, \mathrm{B}, \mathrm{C}(\ldots)$.

$5^{\text {th }}$ Each cluster of the categories: A, B, C(...) resulted in the Discourse of Collective Subjective.
}

Box 2. Steps for the development of the DCS. 
drink water". These ideas produced the Discourse of Collective Subject representing the understanding of the population studied in relation to their concept of healthy eating (Table 1)

The key expressions generated the central ideas which resulted in the students' discourses about healthy eating (Box 3).

The second and last question analyzed the adolescents' perceptions of their own diet, focusing on the way they classified their diet-healthy or unhealthy. Most of them

Table 1. Proportion (\%) of the key-expressions referring to the answers to the first question. São Paulo, Brazil, 2009.

\begin{tabular}{lc}
\hline A: It's to have a balanced and varied diet. & $52.6 \%$ \\
B: It's to eat fruits and vegetables. & $35.1 \%$ \\
C: It's to control fat, sweet, pasta and salt. & $7.3 \%$ \\
D: It's to eat at regular times. & $3 \%$ \\
E: It's to drink water. & $2 \%$ \\
\hline
\end{tabular}

Central idea A-It's to have a balanced and varied diet.

DCS-A: In my opinion healthy eating is a varied and balanced diet with fruits and vegetables, a lot of greens. It's to eat potatoes, beef, chicken, beef liver, fish, eggs, cheese, grains such as rice, beans, soy and linseed, pasta with tomato sauce and French fries. Also, it's to drink natural juices and soft drinks.

Subjects: $\mathbf{n}=\mathbf{5 1}$

Central idea B-It's to eat fruit and vegetables.

DCS-B: Healthy eating is to eat nutritious foods, such as vegetables and fruits (apple and banana) and to drink natural fruit juices. It's a diet with a lot of salads, with every kind of vegetables you like, for example, carrots. Fruits and vegetables are very good for the body, the health and they prevent you from being obese.

\section{Subjects: $\mathbf{n}=\mathbf{3 4}$}

Central idea C - It's control of fat, sweet, pasta and salt.

DCS-C: It's a balanced diet without too much salt and just a little sugar and few sweets, but not in excess. It's to have a light meal: control your fat intake, not eating junk food or pasta.

Subject: $\mathbf{n}=\mathbf{7}$

Central idea D-It's to eat at regular times.

DCS-D: Eating healthily for me is eating well at regular times.

Subjects: $\mathbf{n}=\mathbf{7}$

Central idea E-It's to drink water.

DCS-E: For me healthy eating is drinking a lot of water.

Subjects: $\mathbf{n}=\mathbf{2}$

Box 3. Discursive of Collective Subject referring to question 1. São Paulo, Brazil, 2009.
(56.3\%) recognized their own diet as being healthy, and 42.5\% didn't recognize it as healthy. In both situations they justified its adoption (enablers and barriers). Just $1.2 \%$ of the group was not able to identify if their diet was healthy or not. This question generated 87 key expressions and 3 central ideas (Table 2) that resulted in the Discourse of Collective Subject (Box 4).

\section{Discussion}

\subsection{P.E. Class Is Not a Blast among Girls: Participation of Boys and Girls in the Survey}

The survey on the adolescents' knowledge and perceptions about healthy and unhealthy eating was conducted during Physical Education class. Having gotten the authorization from the school board to collect the data in P.E class or at recess time, we decided that P.E class would help us to have a larger number of participants, since at recess they wouldn't be willing to answer the question

Table 2. Proportion (\%) of the key-expressions referring to the answers to the second question. São Paulo, Brazil, 2009.
A: Yes, I consider it healthy.
$56.3 \%$
B: No, I don't consider it healthy.
$42.5 \%$
C: I don't know.
$12 \%$

Central idea A-Yes, I consider it healthy.

DCS-A: Yes, I consider my diet healthy because I eat a lot of fruits and vegetables, rice and beans, and meat. I don't like it and don't usually eat foods rich in fat and sugar. I think a healthy diet is not bad because we can grow up and be strong. Our arms and legs get strong to run and play, our teeth get strong and beautiful and we don't get sick too often. Moreover, my mother prepares my healthy meals, I eat at regular times and as much as my stomach can handle. I also follow the advice from a dietitian.

Subject: $n=49$.

Central ideal B-No, I don't consider it healthy

DCS-B: No, because on most days I consume the same kinds of foods - some are healthy and others not so much. I eat too many sweeties, like, sandies and cookies, candies, lollipops and sweets in general, and I drink soda. I also eat a lot of fried and fatty foods, such as French fries, snack chips, hot dogs and pasta. I don't normally eat fruits and vegetables. However, to make up for this situation I practice a lot of physical exercise.

Subject: $\mathbf{n}=\mathbf{3 7}$

$$
\text { Central idea } C-I \text { don't know }
$$

DCS-C: I don't know

Subject: $\mathbf{n}=\mathbf{1}$

Box 4. Discourse of Collective Subject referring to question 2. São Paulo, Brazil, 2009. 
naire. The highest proportion of girls (60.2\%) answering to this survey could be due to the time when the data was collected. During P.E. class, although both boys and girls practice physical activities, girls tend to be less engaged in them. They are more willing to devote some of the time to answering the questionnaire. Boys prefer to practice physical activities, such as playing soccer, and don't want to be disturbed during them. GARCIA et al. [25] found a highest prevalence of boys who practiced an intense physical activity (92.4\%), while only $44.3 \%$ of girls practiced it. As to the eating patterns, physical activity can be a potential determinant of the adolescents' nutritional status, normal weight, positivity related to the physical activity (moderate to intense) [26,27].

\subsection{Food Meanings and Preferences: Healthy or Unhealthy?}

This qualitative study is unique in providing a deep account of young people's knowledge and perceptions of healthy eating from the viewpoint of the Brazilian adolescents from the city of São Paulo, Southwest region of Brazil. The qualitative viewpoints reported by the participants are broadly in accordance with a previous research $[10,14,28]$, suggesting that there are several important individual, social, physical and environmental determinants for the adolescents' diet, as it was mentioned by NEUMARK-SZTAINER et al. [9], ESTIMA et al. [11] and TORAL et al. [29]. However, the results from this study also contribute to research in the area and highlight the importance of understanding how youth perspectives diverge and converge.

In this qualitative study, the results from the Discourse of Collective Subject showed that while adolescents have a good understanding of what eating healthily means, nutritional knowledge may not be the main determinant of food choice. Rather, food preferences and taste appear to be the ultimate motivation for young people's food choices. Other determinants also appear as the motivation for their diet, such as hunger and cravings, convenience, availability, parental and peer influence, perceived benefits and body image. These factors were more important than their own knowledge $[9,11,14]$.

Some participants misunderstood the meanings of a healthy diet when they mentioned French fries and soft drinks as being healthy. They may have referred to these foods as their preferred ones and this might be the reason why they considered them healthy. On the other hand, NOBLE et al., [15] found out that adolescents had very definite views on which foods are "healthy" and which are "unhealthy" and which ones they preferred.

NOBLE et al. [15] discussed that the concept of "healthiness" had little influence on food choices. They showed that dishes and foods most frequently chosen for the "healthy" meal were mainly those chosen least frequently for the "preferred" meal and vice versa, implying that the perceived healthiness of the foods is not at all important in children's food choices. In fact, it would appear that it is almost a deterrent or "if it is healthy, I don't like it", and "I like it. it can't be healthy". Foods such as quiche and meat mince, boiled potatoes and rice, mixed vegetables and cabbage, and apple pie were the foods in each group perceived to be the healthiest, but least preferred. Conversely, sausages and pizza, chips and "potato smiles", baked beans and spaghetti in tomato sauce, and ice cream with chocolate sauce were the foods in each group given high-preference rankings but perceived to be less healthy.

\subsection{Dichotomization of Foods}

Several students dichotomized foods into healthy and unhealthy when classifying them. They claimed that healthy foods were those that were "natural", such as fruits and vegetables and unhealthy foods were artificial and high in fat, sugar, salt and/or refined carbohydrates. This was shown in the literature $[13,16]$ and was indicated in the Brazilian food pyramid [30], with whole wheat bread, cookies, pasta and rice, fruits and vegetables, meats and eggs, milk, yogurt and cheese, beans and on the top, to be consumed moderately, fat and oils and sugar and sweets.

\subsection{Determinants of Food Choices}

Youth also associated being at home with consuming healthy foods as it was said: “(...) my mother prepares my healthy meals (...)". This result is related to another important determinant which is availability. Nevertheless, it does point out the important role of the family and the home in healthy eating, particularly when leisure outside the home involves fast food [13]. Also, discussed by PROTUDJER et al. [31] it was identified that sound nutrition symbolized a need for and a means by which family ties were maintained.

Furthermore, it highlights the fact that teenagers are at a critical time of their lives for interventions, as the proportion of young people who engage in family meals decreases with age. The decrease in the number of meals shared with their families may be due to the adolescents' desire for independence from family as they become older [13].

Adolescents living in urban areas are attracted to fast food because food establishments sell a large variety of this kind of food at a low price. In contrast, adolescents who live in suburban areas have less access to these establishments, and thus may eat less fast-food. Therefore, economy together with availability have an impact on their individual food choices [32].

Moreover, the consumption of unhealthy foods rich in 
fat, sugar and salt, represented by soft drinks, potato and corn snack chips, hot dogs, finger foods, ice cream, chocolate, candies, lollipops, and cookies is increasing because of urbanization, economic growth, and influences from the American culture [32].

The dichotomization of foods into healthy and unhealthy is also associated with weight loss, concern with weight and physical appearance, good health and self control. As indicated in the following discourse: “(...) Fruits and vegetables are very good for the body, health and prevent you from being obese (...) a healthy diet is not bad because we can grow up and be strong. Our arms and legs get strong to run and play, our teeth get strong and beautiful and we don't get sick too often (...)”. Weight concern is more common among girls and acts as an important determinant for their food choices [9,13, 17,31]. Some adolescents, mainly the girls, when eating fast and junk food feel a need to apologize or provide excuses; eating such foods can be associated with feelings of guilt, loss of control, and disgust. However, being with a peer group can also lead them to make these choices [31].

\subsection{How Easy or Difficult Is It for Adolescents to Perceive Their Diet as Healthy?}

As reported by NOBLE et al. [15] and TORAL et al. [29] it seems sometimes difficult for young people to perceive what their actual diet is like, if it is healthy or unhealthy. Many of the students were unable to give reasons for their perceptions-vague terms such as "healthy", "full of goodness", and "good for you" or "unhealthy" or "bad for you" are commonly used by them. Where reasons were given, the most frequent one was the presence of specific foods, ingredients or nutrients (fruits, vegetables and fat), even if they were only present in very small quantities as garnishes. Other reasons given revealed different levels of awareness of the sources and functions of foods and nutrients as well as of the understanding of the correlation between food and health.

Considering that a diet involves the consumption of an assortment of foods and beverages, the difficulty in perceiving their diet may be related to the establishment of food patterns and not just only to the consumption of food. Most of the adolescents don't reflect on their food practices. On the other hand, it is believed that during this period of life the individuals have already incorporated the "social desire" to have a healthy diet. In other words, they know that it is expected from them to claim that they eat healthily, as a way not to frustrate both the researcher and their peers' expectations [29].

Another reason for this difficulty can be attributed to the fact that people frequently don't have sufficient instruments to evaluate their own diet. About 40 to $70 \%$ of the population claims that a change in their food consumption is not necessary, once they view their own diet as healthy. This idea is contradictory, considering the growing prevalence of overweight and chronic diseases associated to eating practices which are ever more distant from what is recommended in the dietary guidelines [29].

\section{Conclusions}

In spite of the adolescents' simple answers to define the meaning of healthy and unhealthy eating, they demonstrated to have an adequate knowledge about healthy eating patterns, identifying the key determinants for achieving an adequate diet, focusing on food characteristic and on individual and social aspects The findings of this study suggested that the focus of the traditional nutritional interventions related to basic information about the meanings of healthy eating should be modified. Intervention strategies that focus on behavioral changes should be used due to the difficulty in achieving healthy habits, and the earlier a healthful habit is incorporated the better it can be consolidated in later periods of life (adulthood and old age).

\section{Authors Contributions}

All authors participated in the study and made substantial contributions in the conception and design of the study, acquisition of data, analysis and interpretation of data, drafting the article or revising it critically for important intellectual content. ACBL wrote and reviewed the manuscript, STP reviewed the manuscript and ECTS helped to analyze the qualitative results.

\section{REFERENCES}

[1] S. R. Daniels, et al., "Overweight in Children and Adolescents. Pathophysiology, Consequences, Prevention and Treatment," Circulation, Vol. 111, No. 15, 2005, pp. 1999-2012. doi:10.1161/01.CIR.0000161369.71722.10

[2] M. M. Abrantes, J. A. Lamonier and E. A. Colosimo, "Prevalência de sobrepeso e obesidade nas regiões Nordeste e Sudeste do Brasil," Revista. Associação de Medicina Brasileira, Vol. 49, No. 2, 2003, pp. 162-166. doi:10.1590/S0104-42302003000200034

[3] J. Traebert, "ransição Alimentar: Problema Comum à Obesidade e à Carie Dentária,” Revista de Nutrição, Vol. 17, No. 15, 2004, pp. 247-53. doi:10.1590/S1415-52732004000200011

[4] IBGE-Instituto Brasileiro de Geografia e Estatística, Pesquisa de Orçamentos Familiares 2008-2009: Antropometria e Estado Nutricional de Crianças, Adolescentes e Adultos no Brasil,” Rio de Janeiro, 2010.

[5] ADA-American Dietetic Association, "Position of the American Dietetic Association: Nutrition Guidance for Healthy Children Ages 2 to 11 Years. Journal of American Dietetic Association, vol. 108, No. 6, 2008, pp. 1038- 


\section{7. doi:10.1016/j.jada.2008.04.005}

[6] G. Kourlaba et al., "Dietary Patterns in Relation to SocioEconomic and Lifestyle Characteristics among Greek Adolescents: A Multivariate Analysis," Public Health Nutrition, Vol. 12, No. 9, 2008, pp. 1366-1372. doi:10.1017/S1368980008004060

[7] C. C. P. Estima, et al., "Meal Consumption Patterns and Anthropometric Measurements in Adolescents from a Low Socioeconomic Neighborhood in the Metropolitan Area of Rio de Janeiro, Brazil,” Appetite, Vol. 52, No. 3, 2009, pp. 735-739. doi:10.1016/j.appet.2009.03.017

[8] K. E. Storey, et al., "Determinants of Diet Quality among Canadian Adolescents," Canadian Journal of Dietetic Practice and Research, Vol. 70, No. 2, 2009, pp. 58-65. doi:10.3148/70.2.2009.58

[9] D. Neumark-Sztainer, et al., "Factors Influencing Food Choices of Adolescents: Findings from Focus-Group Discussions with Adolescents," Journal of American Dietetic Association, Vol. 99, No. 8, 1999, pp. 929-937. doi:10.1016/S0002-8223(99)00222-9

[10] M. Story, D. Neumark-Sztainer and S. French, "Individual and Environmental Influences on Adolescent Eating Behaviors," Journal of American Dietetic Association, Vol. 102, No. 3, 2002, pp. S40-S51. doi:10.1016/S0002-8223(02)90421-9

[11] C. C. P. Estima, S. T. Philippi and M. S. Alvarenga, "Factores Determinantes do Consume Alimentar: Por Que os Indivíduos Comem o que Comem?” Revista Brasileira de Nutrição Clinica, Vol. 24, No. 4, 2009, pp. 263-268.

[12] J. P. Taylor and M. McKenna, "Determinants of Healthy Eating in Children and Youth," Canadian Journal of Public Health, Vol. 96, No. 3, 2005, pp. S20-S26.

[13] M. Harrison and L. A. Jackson, "Meanings that Youth Associate with Healthy and Unhealthy Food," Canadian Journal of Dietetic Practice and Research, Vol. 70, No. 1, 2009, pp. 6-12. doi:10.3148/70.1.2009.6

[14] A. Fitzgerald, C. Heary, E. Nixon and C. Kelly, "Factors Influencing the Food Choices of Irish Children and Adolescents: A Qualitative Investigation,” Health Promotion International, Vol. 25, No. 3, 2010, pp. 289-298. doi:10.1093/heapro/daq021

[15] C. Noble, M. Corney, M. Eves, M. Kipps and M. Lumbers, "Food Choice and School Meals: Primary SchoolChildren's Perceptions of the Healthiness of Food and the Nutritional Implications of Food Choices," International Journal of Hospitality Management, Vol. 19, No. 3, 2000, pp. 413-432. doi:10.1016/S0278-4319(00)00038-4

[16] E. M. Rodrigues and M. C. F. Boog, "Problematização Como Estratégia de Educação Nutricional Com Adolescentes Obesos,” Caderno de Saúde Pública, Vol. 22, No. 5, 2006, pp. 923-931. doi:10.1590/S0102-311X2006000500005

[17] M. Kersting, et al., "Food and Nutrient Intake, Nutritional Knowledge and Diet-Related Attitudes in European Adolescents,” International Journal of Obesity, Vol. 32, Suppl. 1, 2008, pp. S35-S41. doi:10.1038/ijo.2008.181

[18] J. E. Harris, et al., "An Introduction to Qualitative Re- search for Food and Nutrition Professionals," Journal of American Dietetic Association, Vol. 109, No. 1, 2009, pp. 80-90. doi:10.1016/j.jada.2008.10.018

[19] H. Günther, "Pesquisa Qualitativa Versus Pesquisa Quantitativa: Está é a Questão?” Psicologia: Teoria e Pesquisa, Vol. 22, No. 2, 2006, pp. 201-210.

[20] A. M. Canesqui, "Pesquisas Qualitativas em Nutrição e Alimentação,” Revista de Nutrição, Vol. 22, No 1, 2009, pp. 125-139. doi:10.1590/S1415-52732009000100012

[21] M. Q. Patton, "Qualitative Research \& Hhealthy Eating: State of Knowledge and Research Gaps," The Nature of Qualitative Inquiry, Thousand Oaks, 2002, pp. 1-35.

[22] F. Lefévre and A. M. C. Lefèvre, "The Collective Subject that Speaks," Interface-Comunicação, Saúde e Educação, Vol. 3, No 1, 2007, pp. 517-524.

[23] D. Jodelet, "Representations Socials: Un Domaine en Expansion,” In: D. Jodelet, Ed., Representation Sociales, PUF, Paris, 1989, pp. 31-61.

[24] M. C. Taylor, “Interviewing,” In: I. Holloway, Ed., Qualitative Research in Health Care, Open University Press, New York, 2005, pp. 39-55.

[25] G. C. B. Garcia, A. M. D. Gambardella and M. F. P. Frutuoso, "Estado Nutricional e Consume Alimentar de Adolescentes de um Centro de Juventude da Cidade de São Paulo,” Revista de Nutrição, Vol. 16, No. 1, 2003, pp. 41-50.

[26] M. Y. Kubik, L. Lytle and J. A. Fulkerson, "Physical Activity, Dietary Practices, and Other Health Behaviors of At-Risk-Youth Attending Alternative High School," Jornal of School Health, Vol. 74, No. 4, 2004, pp. 119124. doi:10.1111/j.1746-1561.2004.tb06613.x

[27] C. P. Mendonça and L. A. Anjos, “Aspectos Das Práticas Alimentares e de Atividade Física Como Determinantes do Crescimento do Sobrepeso/Obesidade No Brasil," Caderno de Saúde Pública, Vol. 20, No. 3, 2004, pp. 698709.

[28] H. Patrick and T. A. Nicklas, "A Review of Family and Social Determinants of Children's Eating Patterns and Diet Quality,” Journal of American Dietetic Association, Vol. 99, No. 3, 2005, pp. 929-934.

[29] N. Toral, M. A. Conti and B. Slater, "A Alimentação Saudável na ótica dos Adolescentes: Percepções e Barreiras à sua Implementação e Características Esperadas em Mmateriais Educativos,” Caderno de Saúde Pública, Vol. 25, No. 11, 2009, pp. 2386-2394. doi:10.1590/S0102-311X2009001100009

[30] S. T. Philippi, "Piramide dos Alimentos: Fundamentos Básicos da Nutrição,” Manole, Barueri, 2008.

[31] J. L. Protudjer, et al., "Children's Perceptions of Healthful Eating and Physical Activity," Canadian Journal of Dietetic Practice and Research, Vol. 71, No. 1, 2010, pp. 19-23. doi:10.3148/71.1.2010.19

[32] L. N. Dapi, et al., "I Eat to be Happy, to be Strong, and to Live, Perceptions of Rural and Urban Adolescents in Cameroon, Africa," Journal Nutrition of Education Behavior, Vol. 39, No. 2, 2007, pp. 320-326. doi:10.1016/j.jneb.2007.03.001 